Scientific Journal of Silesian University of Technology. Series Transport Zeszyty Naukowe Politechniki Śląskiej. Seria Transport

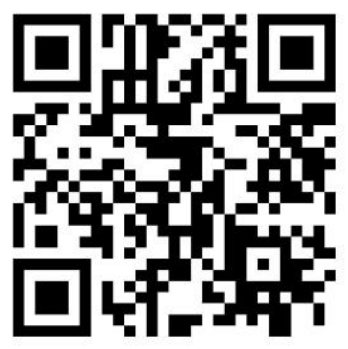

Volume 114

2022

p-ISSN: 0209-3324

e-ISSN: 2450-1549

DOI: https://doi.org/10.20858/sjsutst.2022.114.14

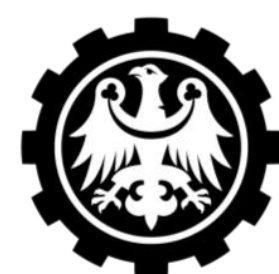

Silesian

University of Technology

Journal homepage: http://sjsutst.polsl.pl

Article citation information:

Vlkovský, M., Malíšek, J. Optimization of the fastening system of the truck using MEMS accelerometers. Scientific Journal of Silesian University of Technology. Series Transport. 2022, 114, 169-178. ISSN: 0209-3324. DOI: https://doi.org/10.20858/sjsutst.2022.114.14.

\author{
Martin VLKOVSKÝ ${ }^{1}$, Jiří MALÍŠEK ${ }^{2}$
}

\title{
OPTIMIZATION OF THE FASTENING SYSTEM OF THE TRUCK USING MEMS ACCELEROMETERS
}

Summary. This paper concerns the possibility of MEMS accelerometers employment in road transportation assessment. It makes use of statistical analysis tools and calculation of securing forces for the sake of road safety enhancement. The transport experiment was carried out and the statistical analysis shows a possible solution to the assessment of shocks during transportation, that in general adversely affect the cargo being transported (cargo securing), the vehicle, the driver, etc. From the results, it follows that even in the case of a high quality road (highway), the values of the shocks at higher speeds considerably exceed the expected magnitudes as defined in the respective standards. The assessment of truck transportation with up-to-date MEMS accelerometers is simple and relatively inexpensive and may represent a considerable contribution to road safety, including associated financial benefits.

Keywords: cargo securing, transport experiment, MEMS accelerometer

\footnotetext{
${ }^{1}$ University of Defence in Brno, Department of Logistics. Kounicova 65, 66210 Brno, Czech Republic. Email: martin.vlkovsky@unob.cz. ORCID: https://orcid.org/0000-0002-0568-7687

${ }^{2}$ University of Defence in Brno, Department of Logistics. Kounicova 65, 66210 Brno, Czech Republic. Email: jiri.malisek@unob.cz. ORCID: https://orcid.org/0000-0003-1610-7585
} 


\section{INTRODUCTION}

Cargo securing on trucks during road transportation is a long-term issue that can be best demonstrated by the estimation provided by the Directorate-General for Mobility and Transport of the European Commission, which states that as many as $25 \%$ of truck accidents are caused by incorrectly or insufficiently secured cargo [1]. The above-mentioned issue arises from either the lack of awareness of the respective cargo securing system requirements or the failure to stick to them (usually due to negligence).

This paper (and related research) concentrates mainly on the unawareness of the respective requirements, which is, however, not given not because of the insufficient qualification of the employee responsible for loading, but because the assumptions of the standards (or possibly other regulations) may not correspond to reality. In particular to lower quality roads or specific trucks (an off-road type), the shocks generated by a vehicle can exceed the normatively determined limits (for example, in ČSN EN 12195-1:2011 standard). Special consideration should also be given to not-fully loaded trucks, where the shocks can be even greater if less than approx. 50\% of the truck effective weight (capacity) is used. Insufficient or inappropriate cargo securing affects road safety, and in the worst case, it can result in a road or other types of accidents (for example, during truck loading/unloading). The financial impact may be expressed by using data from insurance companies [2].

The development of new technologies has brought with it a simple and relatively inexpensive possibility to obtain the required data on selected cases of transportation, evaluate it, and adopt appropriate measures. Hence, the employment of up-to-date MEMS technology-based sensors allowing recording the key data (values of the shocks during transportation) prevents financial losses (damage to goods, trucks, etc.). Larger companies have comprehensive fleet management systems in place, which can acquire and evaluate data from multiple sensors that add to InTransit Visibility (ITV).

Presently, two MEMS accelerometer technologies are commercially available - both with a datalogger, allowing storing primary data in the accelerometer memory or with the online data transfer. Both technologies have their own pros and cons. To provide for accuracy and further data processing, an OMEGA's tri-axial accelerometer with a datalogger and a calibration certificate (shown below) was used during the transport experiment.

The goal of this paper is to assess, using the MEMS accelerometers, transportation using the T-815-7 off-road truck on a highway, without cargo, at maximum technically permissible speed (with the use of a speed limiter).

\section{TRANSPORT EXPERIMENT}

\subsection{Experiment conditions}

The transport experiment was conducted using a T-815-7 M3R31 6x6.1R vehicle with a mileage of almost $12,000 \mathrm{~km}$, without cargo, on the D1 highway between the towns of Hranice and Fulnek (Figure 1).

In total, there were 8 identical journeys at the maximum technically possible speed with the use of a standardly inbuilt speed limiter (technically set to $85 \mathrm{~km} \cdot \mathrm{h}^{-1}$ ). The journeys were only assessed in one direction (Hranice - Fulnek). Hence, the distance was $8 \times 21.2 \mathrm{~km}$ (making the total route length of $169.6 \mathrm{~km}$ ), and the effective average speed during the transport experiment was $85.8 \mathrm{~km} \cdot \mathrm{h}^{-1}$. The transport experiment was conducted under very good climatic conditions 
at $2-4^{\circ} \mathrm{C}$; the highway surface was dry, without snow or ice, and there was no rainfall or snowfall during the experiment. The highway traffic was low and had no impact on the transport experiment itself - the drive in the right lane.

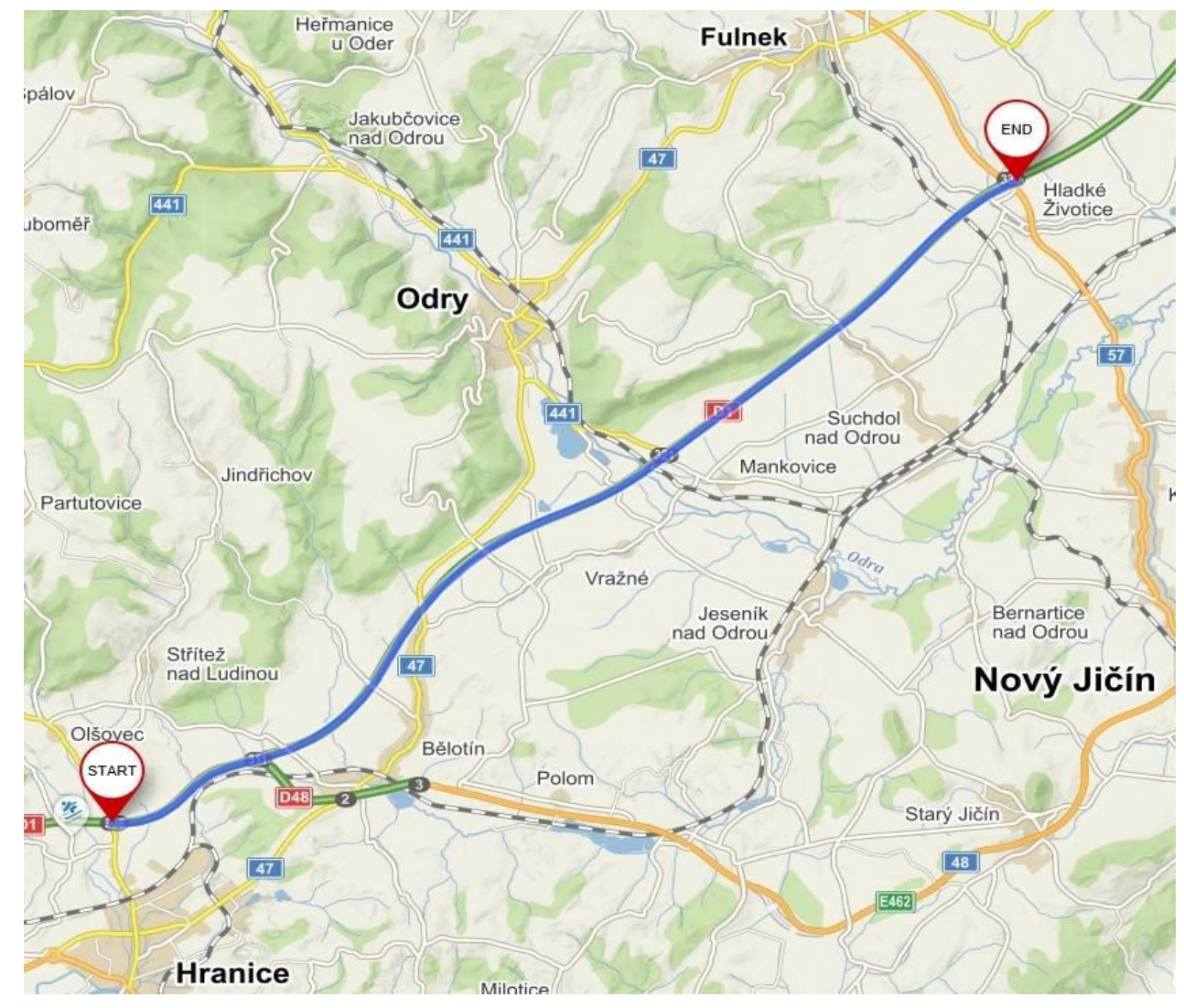

Fig. 1. Transport route

\subsection{Primary data}

For the primary data recording, four tri-axial MEMS OM-CP-ULTRASHOCK-5 accelerometers with a datalogger and a calibration certificate, fixed in the four corners of the cargo space with neodymium magnets, were used. The accelerometers measuring range was $\pm 5 \mathrm{~g}$, and a record was taken every second. The highest (absolute) value was recorded in each axis ( $\mathrm{x}$ - longitudinal, $\mathrm{y}$ - transversal and $\mathrm{z}$ - vertical in the direction of the truck movement) with the sampling frequency of $512 \mathrm{~Hz}$ [3]. In total, 85,356 data was obtained, that is, 21,339 per sensor, which amounts to 7,113 data per axis. The shock values were recorded in the form of the acceleration coefficients, that is, the multiples of normal acceleration of gravity g. For further evaluation, two datasets $\left(d_{\min }\right.$ a $\left.d_{\max }\right)$ were established, each consisting of 21,339 data (7,113 per axis). Dataset $d_{\min }$ (Figure 2) comprises the smallest absolute values from four sensors (accelerometers), always per given axis/second, and analogically, $d_{\max }$ (Figure 3) comprises the highest absolute values from the four sensors (accelerometers) per given axis/second. 


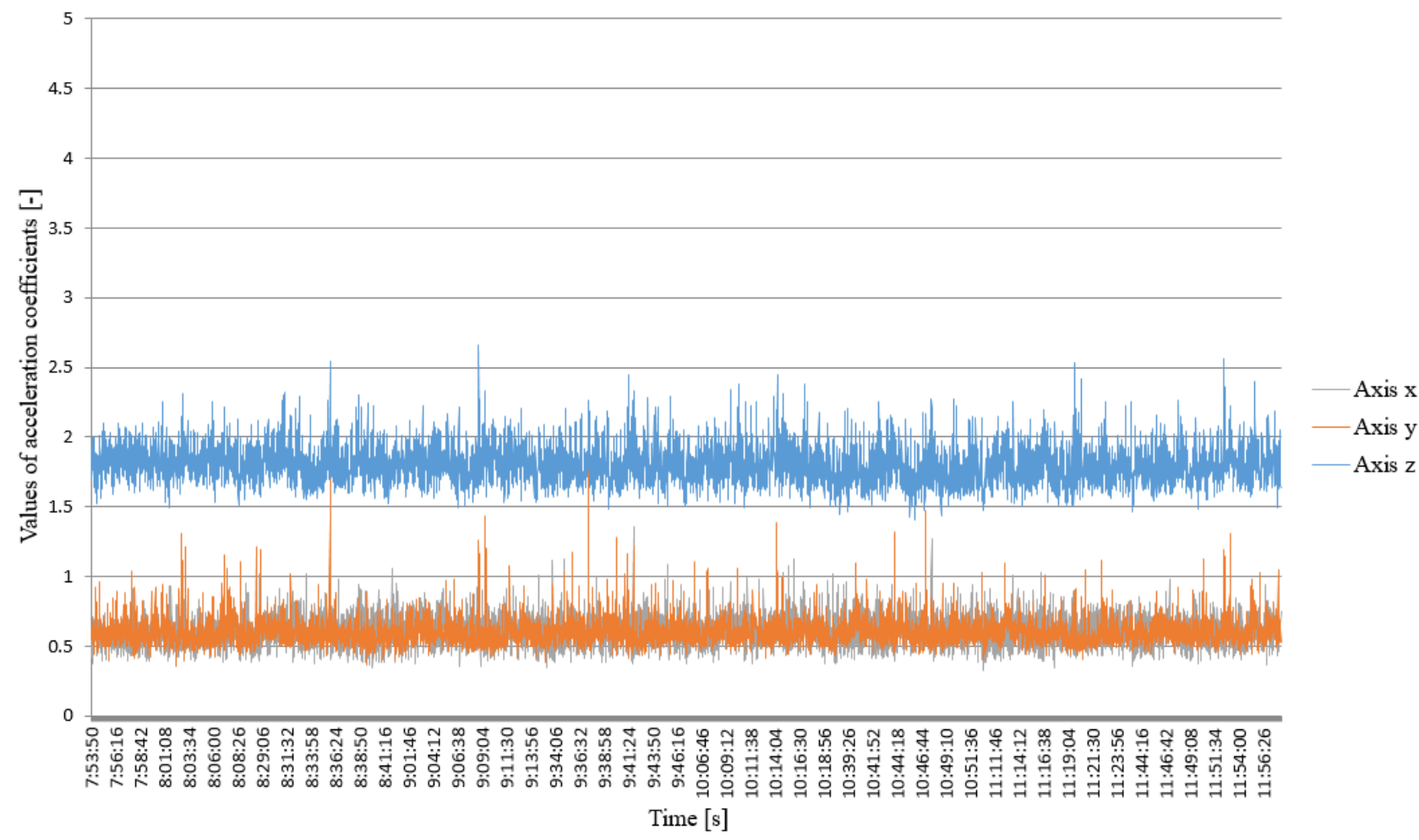

Fig. 2. Primary data $d_{\min }-$ minimum values

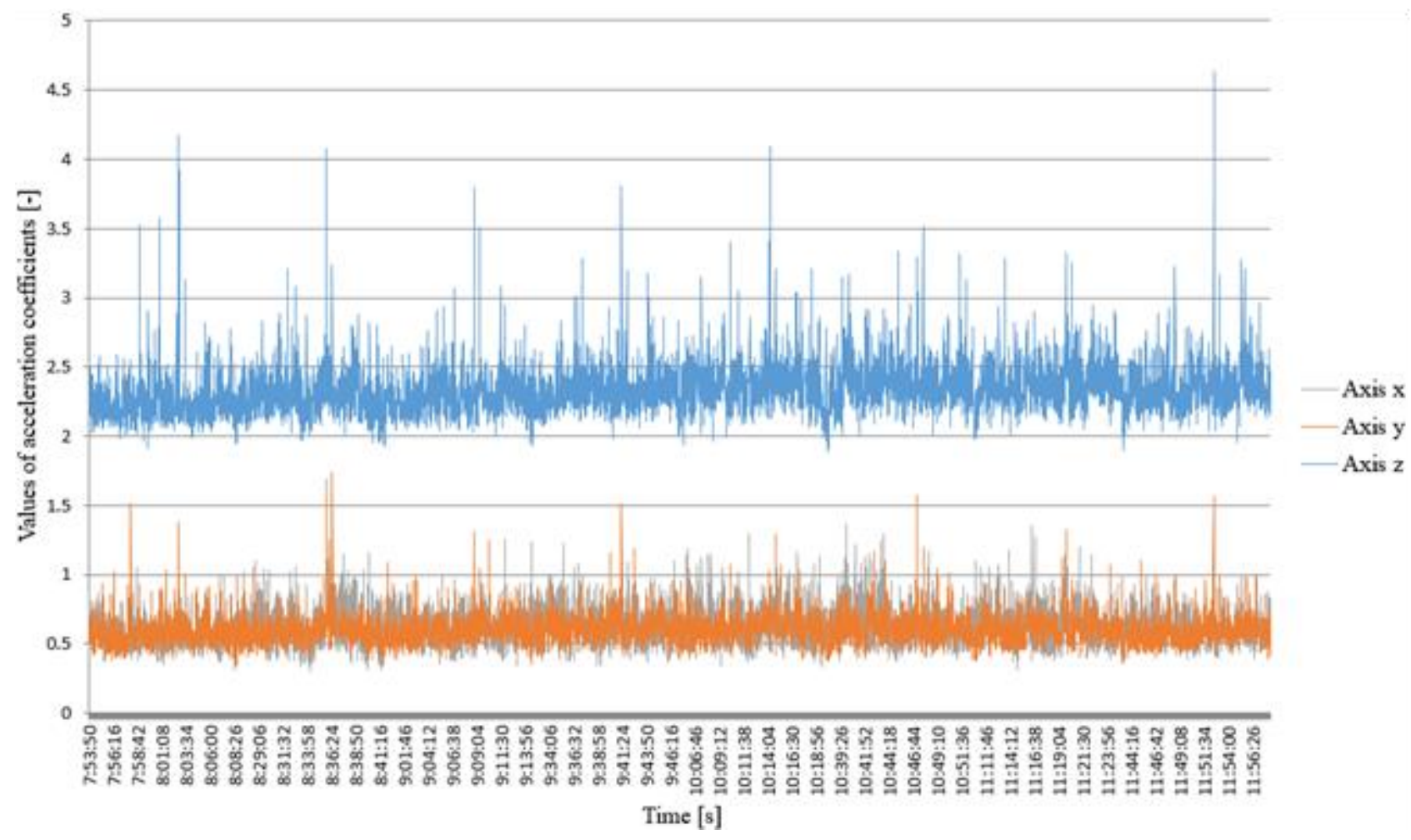

Fig. 3. Primary data $d_{\max }-$ maximum values 


\section{STATISTICAL ANALYSIS}

The data measured - values of the acceleration coefficients - are considered to be the selection of normal distribution, although minor deviations from normality were identified during graphical verification using Q-Q plots. For statistical evaluation of the datasets dmin and dmax, a parametric two-sample t-test was employed. The t-test was taken for all three axes at the level of significance $\alpha=0.05$. The overview of the test results is provided in Table 1 .

Tab. 1

Results of two-sample t-test for all axes

\begin{tabular}{|l|c|c|c|c|}
\hline$c[-]$ & $A_{F}$ & $F$ & $A_{t}$ & $t$ \\
\hline$c_{x}$ & $\sigma_{\min }{ }^{2} \neq \sigma_{\max }{ }^{2}$ & $0.623^{\mathrm{a}}$ & $\mu_{\min } \neq \mu_{\max }$ & $-11.507^{*}$ \\
\hline$c_{y}$ & ${\sigma_{\min }{ }^{2} \neq \sigma_{\max }{ }^{2}}^{2} 0.820^{\mathrm{a}}$ & $\mu_{\min } \neq \mu_{\max }$ & $-1.927^{*}$ \\
\hline$c_{z}$ & ${\sigma_{\min }{ }^{2} \neq \sigma_{\max }{ }^{2}}$ & $0.539^{\mathrm{a}}$ & $\mu_{\min } \neq \mu_{\max }$ & $-197.32^{*}$ \\
\hline
\end{tabular}

* reference to the statistic values, when the corresponding null hypothesis is rejected at the level of significance of $5 \%$

The first column shows the axis, or rather the acceleration coefficients in the respective axis for which the test is carried out. The tests are always performed using datasets comprising both the minimum $\left(d_{\min }\right)$ and the maximum $\left(d_{\max }\right)$ values in the same axis. The second column $(A F)$ states the alternative test hypothesis concerning the homogeneity of variance, and the third column shows the test statistics $(F)$. In the fourth column, there is an alternative test hypothesis concerning the comparison of means followed by the test statistics ( $t$ ) on the condition of heteroskedasticity [4].

Table 1 suggests, at the given level of significance, the existence of the statistically significant difference between datasets $d_{\min }$ and $d_{\max }$. The comparison serves to define the two extreme situations. For the practical application of the experiment outcomes, it is necessary to know the basal vector of the acceleration coefficients for individual axes as per ČSN EN 121951:2011 [5], which is determined as:

$$
c_{x, y, z}=(0.8,0.6,1.0)
$$

In the consequence of the $\mathrm{z}$-axis shift in the measuring device (accelerometer), the normatively determined limit in the z-axis shall be considered as $c_{z}=2.0$. It is only a formal increase by $1 g$; the resting value (formal zero value) in the $\mathrm{z}$-axis is $1 g$.

From Table 2, it clearly arises that the normatively determined limits are relatively often exceeded (at the probability of $17.264 \%$ ) even with the minimum values, mainly due to a high number of excess values in the y-axis $(40.180 \%)$, where the normatively determined value of the acceleration coefficient is the lowest. In the maximum values dataset, the result is very high - more than half of the values (52.088\% of the values), in particular, due to a high number of excess values in the z-axis (almost all values, 99.367\%). The difference between the two datasets is more noticeable when dealing with the values of double excess of the normatively determined limits as the result is negligible for $d_{\min }(0.066 \%)$, but amounts to $0.328 \%$ for $d_{\max }$. In absolute numbers, it is the total of 70 values in $d_{\max }$ that represent possibly dangerous situations as the values of the actual shocks more than double exceeded the normatively determined (assumed) values as per ČSN EN 12195-1:2011 in at least one axis. 
Tab. 2

Differences between selected characteristics

\begin{tabular}{|c|c|c|c|c|c|c|}
\hline & \multicolumn{3}{|c|}{$d_{\text {min }}$} & \multicolumn{3}{|c|}{$d_{\max }$} \\
\hline & $c_{x}$ & $c_{y}$ & $c_{z}$ & $c_{x}$ & $c_{y}$ & $c_{z}$ \\
\hline Arith. m. & 0.613 & 0.599 & 1.799 & 0.637 & 0.603 & 2.336 \\
\hline Variance & 0.012 & 0.010 & 0.018 & 0.019 & 0.012 & 0.034 \\
\hline Prob 1× & 4.260 & 40.180 & 7.156 & 11.402 & 44.510 & 99.36 \\
\hline Prob $2 \times$ & 0.000 & 0.197 & 0.000 & 0.014 & 0.197 & 0.773 \\
\hline
\end{tabular}

Interestingly, the table similarly proves that the arithmetic mean of the minimum as well as maximum values is almost the same in the y-axis, and oscillates around the normatively determined limit $\left(c_{y}=0.6\right)$. In the $\mathrm{z}$-axis $\left(d_{\max }\right)$, the arithmetic mean shows a more significant excess of the normatively determined limit $\left(c_{z}=2.0\right)$.

\section{THE CALCULATION OF THE SECURING FORCES EXTREMES}

The appropriate fastening system with corresponding securing forces shall be selected based on the expected inertial forces. For this paper, a standard method of fastening one model pallet unit (EUR pallet) sized: $1,200 \times 800 \times 1,600 \mathrm{~mm}$ (length $\times$ width $\times$ height) with the total weight of $m=1,000 \mathrm{~kg}$ shall be considered. The pallet unit lied longitudinal to the direction of the truck movement.

The fastening model will make use of a standard textile lashing strap with a corresponding lashing capacity being higher or at least equal to the magnitude of the required securing forces. The model of cargo (pallet unit) securing using a Top-Over Lashing method [6] is shown in Figure 4.

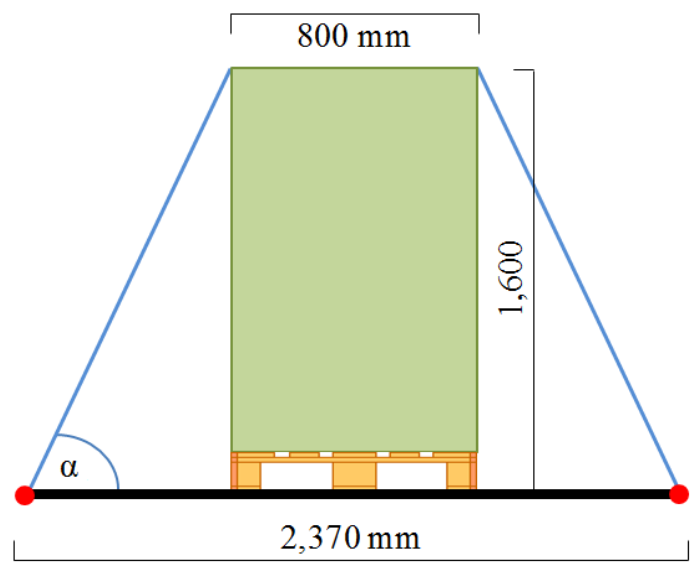

Fig. 4. Model of cargo securing

The securing forces are calculated in compliance with ČSN EN 12195-1:2011, and take the securing forces in the $\mathrm{x}$-axis and $\mathrm{y}$-axis into consideration [10]. In the $\mathrm{z}$-axis, that is, for $F_{z}$, it is assumed that the other two forces are greater and therefore [12] applies:

$$
F_{x} \geq F_{z} \leq F_{y}
$$


For the calculation of the Fx and Fy securing forces, the following formulas are used [10]:

$$
\begin{gathered}
F_{x}=\frac{\left(c_{x}-\mu \cdot c_{z}\right) \cdot m \cdot g}{2 \cdot n \cdot \mu \cdot \sin \alpha} \cdot f_{s} \quad[\mathrm{~N}] \\
F_{y}=\frac{\left(c_{y}-\mu \cdot c_{z}\right) \cdot m \cdot g}{2 \cdot n \cdot \mu \cdot \sin \alpha} \cdot f_{s} \quad[\mathrm{~N}]
\end{gathered}
$$

where $c_{x}, c_{y}$ and $c_{z}$ are the values of the acceleration coefficients in individual axes, $\mu$ is the friction factor, $\mathrm{m}$ is the cargo (pallet unit) weight, $g$ is the normal acceleration of gravity, $f_{s}$ is the safety factor, $n$ is the number of required lashing straps, and $\alpha$ is the angle the lashing strap (Top-Over Lashing) forms with the plane of the cargo space.

For the calculation of the securing forces, the normatively determined coefficients of the standard [10], are employed first (formally designated as $c_{x n}, c_{y n}$ and $c_{z n}$ ) - refer to the formula (1) to cater for the shift of the z-axis, followed by the values of the arithmetic means of the acceleration coefficients in the individual axes (Table 2), or possibly experimentally identified extremes ( Table 3). The tabular value $\mu=0.35$ (for a wood - grooved aluminum) shall be considered for the friction factor, and 1.25 for fs in the x-axis (formally designated as $f_{s x}$, or possibly 1.1 in the $\mathrm{y}$-axis $\left(f_{s y}\right)$ [10]. The $\mathrm{n}$ shall be substituted formally with 1 , that is, the calculation for one textile lashing strap.

Tab. 3

Extremes in both datasets

\begin{tabular}{|l|c|c|c|c|c|c|}
\hline & \multicolumn{3}{|c|}{$d_{\min }$} & \multicolumn{3}{c|}{$d_{\max }$} \\
\hline & $c_{x}$ & $c_{y}$ & $c_{z}$ & $c_{x}$ & $c_{y}$ & $c_{z}$ \\
\hline Extremes & 1.36 & 1.82 & 2.66 & 1.69 & 1.74 & $4.64^{*}$ \\
\hline
\end{tabular}

* actual measured values in the $\mathrm{z}$-axis, that is, including the shift o the coordinate axis $(+1 g)$

The resulting securing forces for the three considered variants (normatively determined, mean values and extremes in each of the datasets) are summarized in Table 3. Possible minor deviations in the magnitude of securing forces $\left(F_{x}\right.$ and $\left.F_{y}\right)$ are caused by the rounding of the input values stated in Table 4.

From Table 4, the required magnitudes of securing forces are calculated in the respective column using the normatively determined limits (values of the acceleration coefficients in the individual axes), the mean values in both datasets, and finally the extremes, that is, the highest measured values per the dataset and the axis.

Tab. 4

Magnitudes of respective securing forces

\begin{tabular}{|c|c|c|c|c|c|c|}
\hline & Unit & Standard & Average $d_{\min }$ & Average $d_{\max }$ & Extremes $d_{\min }$ & Extremes $d_{\max }$ \\
\hline$m$ & {$[\mathrm{~kg}]$} & 1,000 & 1,000 & 1,000 & 1,000 & 1,000 \\
\hline$g$ & {$\left[\mathrm{~ms}^{-2}\right]$} & 9.81 & 9.81 & 9.81 & 9.81 & 9.81 \\
\hline$\alpha$ & {$\left[{ }^{\circ}\right]$} & 63.87 & 63.87 & 63.87 & 63.87 & 63.87 \\
\hline
\end{tabular}




\begin{tabular}{|c|c|c|c|c|c|c|}
\hline $\sin$ & {$[-]$} & 0.86 & 0.86 & 0.86 & 0.86 & 0.86 \\
\hline$c_{x}$ & {$[-]$} & 0.80 & 0.61 & 0.64 & 1.36 & 1.69 \\
\hline$c_{y}$ & {$[-]$} & 0.60 & 0.60 & 0.60 & 1.82 & 1.74 \\
\hline$c_{z}$ & {$[-]$} & 2.00 & 1.80 & 2.34 & 2.66 & 4.64 \\
\hline$n$ & {$[\mathrm{pcs}]$} & 1 & 1 & 1 & 1 & 1 \\
\hline$\mu$ & {$[-]$} & 0.35 & 0.35 & 0.35 & 0.35 & 0.35 \\
\hline$f_{s x}$ & {$[-]$} & 1.25 & 1.25 & 1.25 & 1.25 & 1.25 \\
\hline$f_{s y}$ & {$[-]$} & 1.10 & 1.10 & 1.10 & 1.10 & 1.10 \\
\hline $\boldsymbol{F}_{\boldsymbol{x}}$ & {$[\mathrm{N}]$} & $\mathbf{2 , 0 3 3}$ & $\mathbf{3 4 2}$ & $\mathbf{3 , 6 7 7}$ & $\mathbf{8 , 7 2 4}$ & $\mathbf{1 , 3 4 2}$ \\
\hline $\boldsymbol{F}_{\boldsymbol{y}}$ & {$[\mathrm{N}]$} & $\mathbf{1 , 7 8 9}$ & $\mathbf{5 4 2}$ & $\mathbf{3 , 8 4 4}$ & $\mathbf{1 5 , 9 0 8}$ & $\mathbf{2 , 0 7 6}$ \\
\hline
\end{tabular}

When comparing the results of the calculation of the securing forces with the normative model (the first column), it is evident that the mean values in the minimum values dataset $\left(d_{\text {min }}\right)$ are considerably lower (almost 6 times in the $\mathrm{x}$-axis and 3 times in the y-axis). Regarding the absolute numbers, the magnitudes of average securing forces are negligible. On the contrary, the mean values in the maximum values dataset $\left(d_{\max }\right)$ are considerably higher (by more than $80 \%$ in the $\mathrm{x}$-axis and more than $115 \%$ in the y-axis). Paradoxically, the extreme values in both axes (that is, for $F_{x}$ as well as $F_{y}$ ) show that the values of securing forces are considerably higher in $d_{\min }$ than in $d_{\max }$. It is evident that the inertial forces acting on the cargo nullified each other, thus proving the inappropriateness of the use of the selected extreme in the calculation of securing forces. There is a possibility of evaluating the extremes in advance using an appropriate method (for example, Extreme Value Theory [7, 8]), and then calculating the securing forces. The empirically obtained and averaged values of the normatively determined acceleration coefficients also represent certain limitations, for instance, the value of a numerator in the calculation of $F_{y}$ for $\mu=0.3$, which is a commonly used value for a timber, is zero, which makes the result unusable as a comparative etalon.

For the transportation assessment, it only makes sense to work with $d_{\max }$ with average values. It is apparent that not only the extremes selected but also the arithmetic mean values exceed the normatively determined values in the $y$-axis and the $\mathrm{z}$-axis (by less than $0.5 \%$ in the $y$-axis and by almost $17 \%$ in the z-axis).

\section{CONCLUSION}

From the transport experiment conducted, it follows that it is necessary to analyze selected cases of transportation and identify possible deviations from the assumptions of ČSN EN 12195-1:2011.

In particular, when the normatively determined values of the acceleration coefficients are more than double exceeded, there is an imminent danger of the cargo loosening, which may adversely affect not only the cargo itself, but also the vehicle, and even lead to a truck accident and injure the driver [9].

Up-to-date MEMS technologies (sensors) represent a relatively inexpensive and simple system of data collection, which can subsequently be evaluated not only with the commonly available statistical software but also directly in fleet management applications. At the same time, such technologies represent a simple tool to support management decision-making [10].

The results are mainly applicable to the transportation of hazardous objects when a truck accident could have a much greater impact, or possibly transportation by special vehicles (for example, military, integrated rescue system vehicles). 
The analysis of the cases of transportation may, with the use of the selected data from the sensors (shocks, humidity, temperature, etc.), not only enhance transport safety but also be of economic benefit. Besides extreme cases, such as casualties, damages to health or the environment and great losses to property in the event of road accidents, even a minor excess of the assumed magnitudes of securing forces may result in, for example, shorter life of individual cargo securing system components, the vehicle, and other technical means (for example, pallet, container).

Further research will focus on the analysis of other modes of transport (the rail transport [11], or specific transport objects (for example, bridges, airports [12, 13, 14]). A prerequisite is an application of the new or less commonly employed methods (for example, spectral analysis $[15,16]$.

This research was funded by the Ministry of Education, Youth and Sports of the Czech Republic under the specific research grant No. SV19-FVL-K109-SVA: 'Optimisation of the system of supplying units with material in multinational operations focusing on operational and tactical level'.

\section{References}

1. European Commision - Directorate-General for Energy and Transport. European best practice guidelines on cargo securing for road transport. Available at: www.uirr.com/fr/component/ downloads/downloads/302.html.

2. EC. EUROPA. ,Road Safety: Best Practice Guidelines on Cargo Securing and Abnormal Transport. European Commission - Directorate-General for Energy and Transport”. Available at: https://ec.europa.eu/transport/road_safety/sites/roadsafety/files/vehicles/doc/abnormal_tra nsport_guidelines_en.pdf.

3. ASSETS. OMEGA. „Technical Specifications (2015) Accelerometer - Datalogger”. Available at: https://assets.omega.com/manuals/M3667.pdf.

4. Kucera P., I. Krejci. 2013. "Contribution of Simple Heurisitcs for the Vehicle Routing Problem - A Case Study of a Small Brewery". Acta Universitatis Agriculturae et Silviculturae Mendelianae Brunensis 61(7): 2393-2401.

5. ČSN EN 12195-1:2011. Load Restraining on Road Vehicles - Safety-Part 1: Calculation of Securing Forces. Prague: Czech Office for Standards, Metrology and Testing.

6. Lerher T. 2015. Cargo Securing in Road Transport Using Restraining Method with Topover Lashing. New York: Nova. 86 p.

7. Calvadas J., C.L. Azevedo, H. Farah, A. Ferreira. 2019. "Extreme value theory approach to analyze safety of passing maneuvers considering drivers' characteristics (Periodical style)". Accident Analysis and Prevention 134: 1-10.

8. Zheng L., T. Sayed, M. Essa. 2019. "Validating the bivariate extreme value modeling approach for road safety estimation with different traffic conflict indicators (Periodical style)". Accident Analysis and Prevention 123: 314-323.

9. Bucsuhazy K. et al. 2016. ,,Analysis of Driver Reaction Time Using the Acquisition of Biosignals (Published Conference Proceedings style)". In: Proc. of 3rd Int. Conf. on „Traffic and Transport Engineering - ICTTE Belgrade”. Belgrade. P. 68-74. 
10. Rolenec O. et at. 2019. "Supporting the decision-making process in the planning and controlling of engineer task teams to support mobility in a combat operation (Periodical style)". International Journal of Education and Information Technologies 13: 33-40.

11. Rehak D. et al. 2020. "Integral approach to assessing the criticality of railway infrastructure elements (Periodical style)". International Journal of Critical Infrastructures 16(2): 107-129.

12. Sousek R., P. Viskup, P. Hruza. 2014. "The development and application of evaluation system to the new temporary railway bridge construction in the Czech Republic (Published Conference Proceedings style)". In: Proc. 18th International Scientific Conference ,Transport Means 2014”: 329-334.

13. Sousek R., P. Viskup, P. Hruza. 2014. "The development and application of evaluation system to the new temporary railway bridge construction in the Czech Republic (Published Conference Proceedings style)". In: Proc. 18th International Scientific Conference ,,Transport Means 2014”: 35-37.

14. Korecki Z., B. Adamkova. 2018. "The process of preparation and implementation of the Baltic Ais Policing Task Force (Published Conference Proceedings style)". In: Proc. 22nd International Scientific Conference ,Transport Means 2018”: 822-827.

15. Grzesica D. 2018. "Measurement and analysis of truck vibrations during off-road transportation (Published Conference Proceedings style)". In: 14th International Conf. on Vibration Engineering and Technology of Machinery. Lisbon.

16. Grzesica D., P. Wiecek. 2016. "Advanced forecasting methods based on spectral analysis (Published Conference Proceedings style)". In: Proc. 1st World Multidisciplinary Civil Engineering, Architecture and Urban Planning Symposium: 256-258. Prague.

Received 07.10.2021; accepted in revised form 25.11.2021

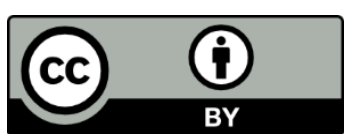

Scientific Journal of Silesian University of Technology. Series Transport is licensed under a Creative Commons Attribution 4.0 International License 